\title{
Acoustic Emission and Surface Roughness in Ultra-Precision Diamond Turning of RSA 6061 for Optics Applications
}

\author{
Odedeyi Peter Babatunde*, Abou-El-Hossein Khaled, Abdulkadir Lukman \\ Precision Engineering Laboratory, Department of Mechatronics, School of Engineering, Nelson Mandela University, South Africa
}

Received July 16, 2021; Revised August 17, 2021; Accepted September 21, 2021

\section{Cite This Paper in the following Citation Styles}

(a): [1] Odedeyi Peter Babatunde, Abou-El-Hossein Khaled, Abdulkadir Lukman, "Acoustic Emission and Surface Roughness in Ultra-Precision Diamond Turning of RSA 6061 for Optics Applications, "Universal Journal of Mechanical Engineering, Vol. 9, No. 2, pp. 11-20, 2021. DOI: 10.13189/ujme.2021.090201.

(b): Odedeyi Peter Babatunde, Abou-El-Hossein Khaled, Abdulkadir Lukman (2021). Acoustic Emission and Surface Roughness in Ultra-Precision Diamond Turning of RSA 6061 for Optics Applications. Universal Journal of Mechanical Engineering, 9(2), 11-20. DOI: 10.13189/ujme.2021.090201.

Copyright $\bigcirc 2021$ by authors, all rights reserved. Authors agree that this article remains permanently open access under the terms of the Creative Commons Attribution License 4.0 International License

\begin{abstract}
Machining Rapidly Solidified aluminium (RSA) 6061, a widely used optical material by Ultra-high precision diamond turning, has enabled high accuracy and surface integrity. However, improved quality and productivity require precision surface and machining process monitoring because the duo has a great influence on machine part performance. The study presented in this paper investigates the effects of cutting parameters (i.e., depth of cut, feed rate and cutting speed) on machining output variables (surface roughness and acoustic emission potentials) during ultra-high precision diamond turning of RSA 6061. With the aid of Box-Behnken design (BBD), a response surface methodology, and the analysis of variance (ANOVA), the correlation between cutting parameters and machining output variables were analyzed and modeled. The results showed that both surface roughness and acoustic emission potentials are greatly influenced by feed rate and cutting speed. For a better-quality surface roughness and low acoustic emission during ultra-high precision diamond turning of RSA 6061, high cutting speed and low feed rates are the right combinations and vice versa.
\end{abstract}

Keywords Acoustic Emission, Surface Roughness, Ultra-high Precision Diamond Turning, ANOVA, RSA 6061

\section{Introduction}

With the widespread application of optics and electronic data developments in some areas of technology such as aerospace, defense, military, biomedical, electronics, astronomy etc., optical components are being produced with high-surfaces quality which has extended and intensify the degree of precision necessity for machining and evaluation [1]. The role of process and surface monitoring in ultra-precision manufacturing is very crucial in that two bodies in contact leads to friction which ultimately causes continuous change in factors that predicts surface generation. Since surface generation involves many mechanisms $[2,3]$, different experimental methods have been adopted to analyze surface roughness mechanism in the static state, while a number of advanced models have been employed to attain material surfaces with preset roughness parameters being proposed [3-5]. But some of these surface generation mechanisms are still far researched due to the absence of direct access to the breach between surfaces during frictional contact. Acoustic phenomenon has shown to be a capable way to monitor the state of surface finish during diamond turning. Basic optical materials utilized in the assembling of optics are steel, aluminum and tungsten carbide. These materials are chosen because of their heat obstruction, introspective properties, and trademark quality. Be that as it may, the utilization of fine small-scale micro-structure rapidly 
solidified aluminum (RSA) alloys in manufacturing of optical form inserts has as of late grown because of their functionality at moderately low cost. RSA alloys fine microstructure which is a reason for its high quality makes them appropriate candidates for making shapes for engineering materials [6]. Situ tracking systems that can be used to describe, manipulate, and improve the fabrication of those micro features are therefore needed to meet the growing need in terms of precision and quality. Sensor-based monitoring system generates significant data about the fabrication procedure that could serve a double purpose of procedure management and quality monitoring which will in the end be a part of any fully automated production environment $[7,8]$. However, a high reliability and degree of confidence is required from this (AE) sensor-based monitoring tool to fully describe the targeted manufacturing process. Hence, acoustic emission has proven to possess these characteristics of high quality in manufacturing even at nano level.

\subsection{Surface Roughness}

A manufacturing surge has been experienced in the progress of modified aluminium alloy grades with an improved ability for optical moulds and surfaces. Although this development in ultra-high precision diamond turning is targeted at improving productivity at the same time retain satisfactory and desired surface finish quality, to the acknowledgement of newly created advance foundry. Melting techniques are used in melt-spinning technology to produce these super alloys. These super alloys possess fine microstructures that enable and enhance their superior physical and mechanical properties. However, recent studies on aluminium alloys have shown improvement in its machinability and capabilities for mould inserts. Zhang et al. [9], examined the performance in terms of surface roughness of the moulds inserts made out of aluminium alloy of grades: RSAL, 6061L and berrylium copper. They came to a conclusion that RSAL was better than the other two due to its fine microstructure [10]. Gubbels et al [11] conducted an experimental study on RSA 6061 with a $0^{0}$ rake angle. They established that this modified alloy has a low surface roughness of between $2-3 \mathrm{~nm}$ which is far less compared to what is obtainable in conventional aluminium alloys [10]. Otieno et al [12] investigated the machinability of RSA 905 by considering the effect of cutting parameter on surface roughness. They reported that better quality was achieved with low feed rates. However, looking closely at literature it can be found that research activities on this advanced rapidly aluminium alloy (RSA) 6061 are still insufficient. Therefore, there is a need for more explorations on this material for better performance.

\subsection{Acoustic Emission}

Acoustic emission (AE) monitoring of material removal process during machining is a well-researched area in manufacturing. AE has been applied in different types of machining process such as milling, drilling, grinding, turning etc. AE has also been found very useful in the area of interest in single point cutting such as Single point diamond turning (SPDT). According to literature, AE was applied widely in SPDT to monitor the relationship between cutting state and parameter of interest such as wear, surface roughness, vibration, cutting force etc. [13-18]. Due to accuracy of part performance, manufacturing of high precision lens for moulds demands precise tool and machine sets up. Hence, many researchers have adopted $\mathrm{AE}$ to monitor machinability of some promising advanced materials for over 25 years in ultra-precision manufacturing [16, 19]. Optical materials such as Silicon, RSA alloys, Ceramics, Polymers and Glass have taken advantage of $\mathrm{AE}$ process to optimize their functionalities [6, 20-22]. Pawade and Joshi [23], investigated surface quality of 7050-T7451 aluminium alloy and Inconel 718 at a high cutting speed in turning process. They concluded that $\mathrm{AE}$ indicators are associated with reduced perturbations in energy and count profiles which specify a better surface finish [8]. According to Wang and Liu [8], it was noted that high cutting speed was associated with high AE signals in their studies during machining process of 7050-T7451 aluminium alloy. They further explored the relationship between the AE with chip formation and cutting energy consumption. They found out that the frequencies recorded for serrated chips of the workpiece material at high cutting speed are almost the same as the frequency of the AE domain [8]. Olufayo and Abou-El-Hossein adopted acoustic emission system to monitor tool wear rate during Ultra-precision machining of RSA 905. They recorded a substantial sharp rise in acoustic emission RMS with a consequent increase in tool wear pattern on the tool wear measurement [6]. Otieno and Abou-El-Hossein also confirmed in their studies that there is a direct correlation between acoustic emission signal and tool wear state while diamond turning RSA 905 [24].

\section{Materials and Methods}

The workpiece used in this study is Rapidly Solidified Aluminium alloy (RSA) 6061 of $80 \mathrm{~mm}$ diameter size. The alloy was diamond turned using three different machining parameters based on BBD combination as shown in Table 2. The machining parameters used are depth of cut, cutting speed and feed rate. The parameters domains were as follows: depth of cut $5-25 \mu \mathrm{m}$, cutting speed $500-$ $3000 \mathrm{rpm}$ and feed rate $5-25 \mathrm{~mm} / \mathrm{min}$. The choice of these parameters was based on literatures and studies conducted on RSA by different authors $[12,20,25-28]$. The experiments were performed on Precitech Nanoform ${ }^{\circledR} 250$ Ultra grind machine (Figure 1). Acoustic emission sensor from Kistler Type 8152B Piezotron AE Sensor was 
attached to the tool holder which was connected to Kistler Piezotron Coupler Type 5125B. National Instruments, NI PXIe-1071 chassis was used in conjunction with the NI BNC-2110. The BNC-2110 serves as an attachment point for instruments with BNC connections. The PXIe-1071 operates at $+/-12 \mathrm{~V} \mathrm{DC}$ with an accuracy of $0.008 \mathrm{~V}$ and can sample at a maximum of $200 \mathrm{kS} / \mathrm{sec}$. This system is attached to a PC with the NI LabView 2019 software. LabVIEW is an NI program that was initialized with continuous sampling measurement and 10000 samples to read at a rate of $1000 \mathrm{kHz}$ to adequately monitor and capture the acoustic emission data which was saved as a text file in Microsoft excel. The acquired raw data (Time domain) were filtered and the remaining signal was analyzed in frequency domain using Matlab software system. The experimental setup as described in (Fig. 1 and Fig. 2) ware used for the turning operations of RSA 6061 and AE data acquisition system. The workpiece was installed on a spindle via a vacuum chuck with the help of an adapter that fastened the workpiece, the diamond cutting tool was firmly attached to the tip of the tool holder, and this was then clamped onto a tool post. A profilometer was used to measure the surface profile at the end of each experimental run. Table 1 shows the chemical properties for RSA Alloy. Design Expert software using Box Behnken design of Experiment (DOE) and Excel software were combined to analyze the output data. Analysis of variance (ANOVA) was carried out on both proposed acoustic emission and surface roughness models.

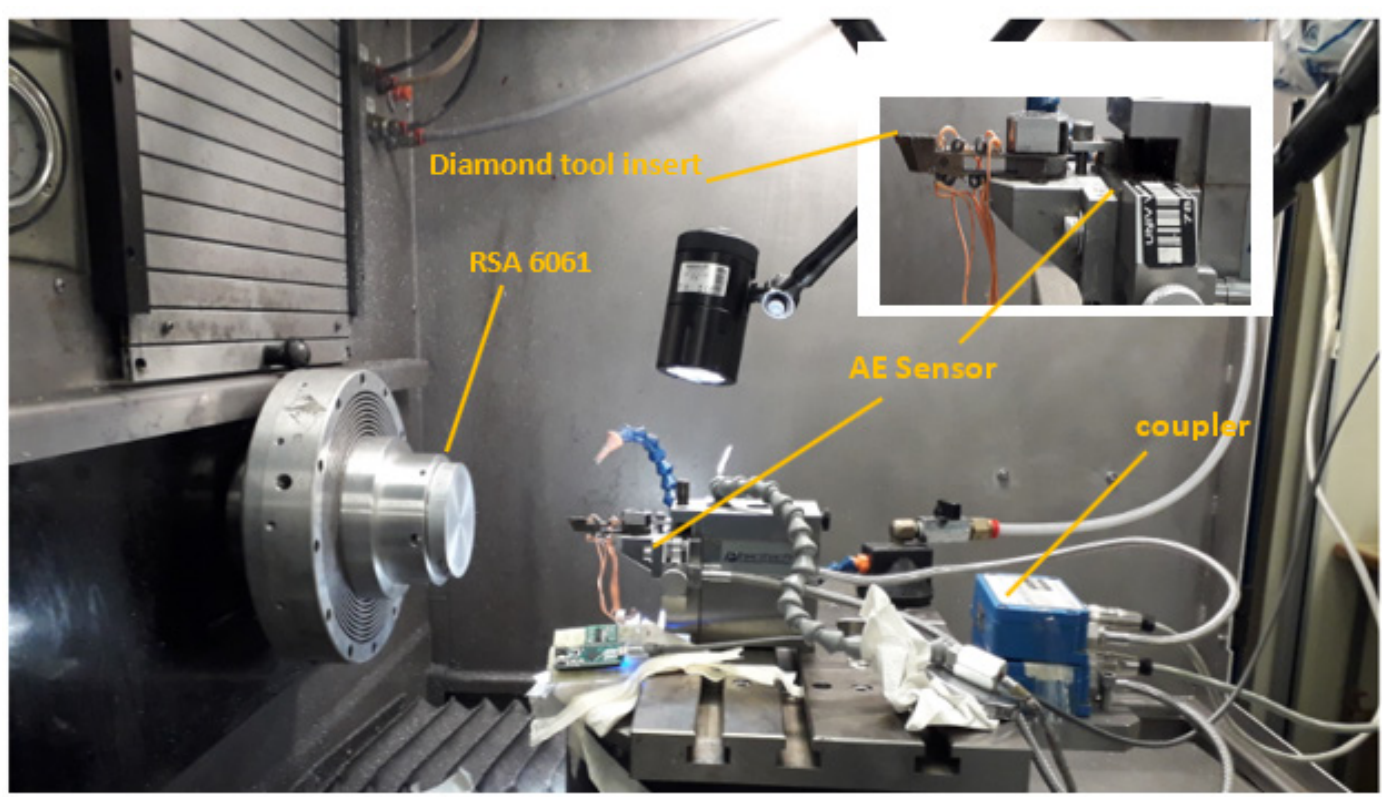

Figure 1. Experimental set up

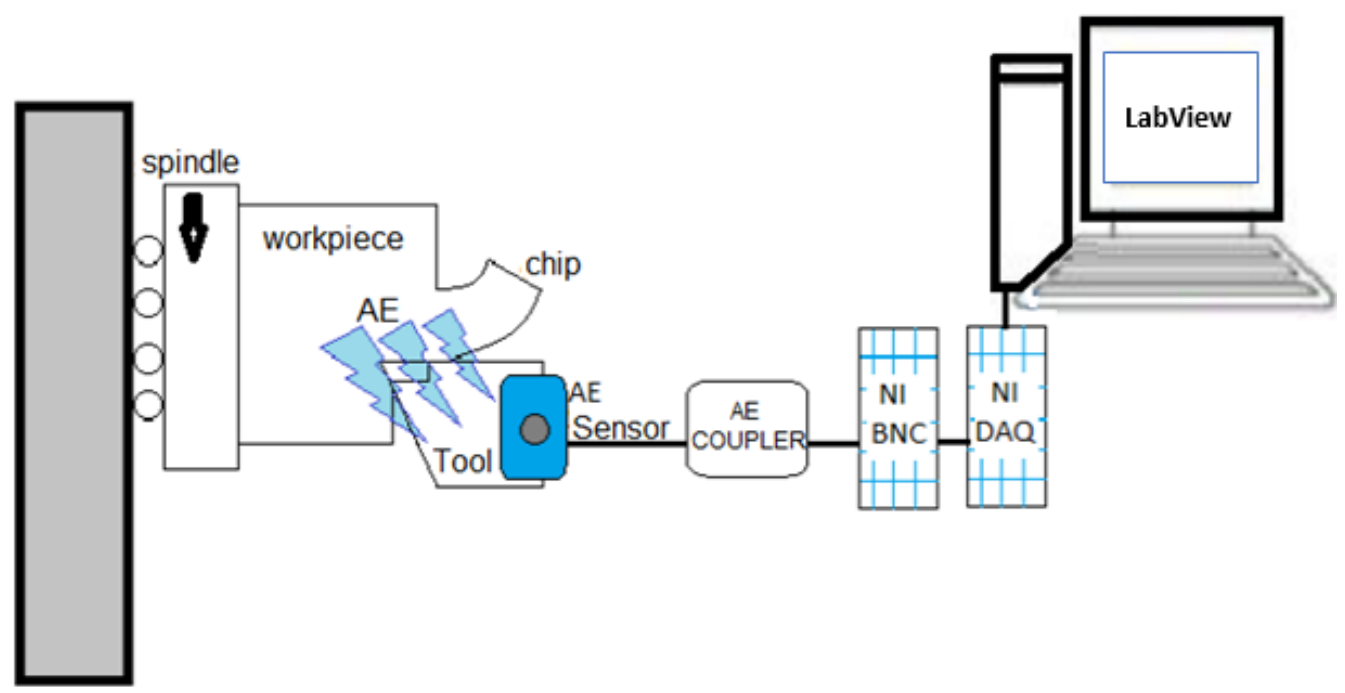

Figure 2. Schematic illustration of $\mathrm{AE}$ acquisition system 
Table 1. Chemical properties of RSA alloys [29]

\begin{tabular}{|c|c|c|c|c|c|c|c|c|c|}
\hline & $\mathbf{S i}$ & $\mathbf{F e}$ & $\mathbf{C u}$ & $\mathbf{M g}$ & $\mathbf{Z r}$ & $\mathbf{C r}$ & $\mathbf{M n}$ & $\mathbf{T i}$ & $\mathbf{A l}$ \\
\hline RSA 6061 & 0.6 & 0.2 & 0.3 & 1 & 0.1 & 0.2 & 0.1 & 0.1 & 97.4 \\
\hline
\end{tabular}

\section{Results and Analysis}

Table 2 presented the acoustic emission and surface roughness data acquired during ultra-precision machining of RSA 6061. Looking closely at raw data, among the three cutting parameters, it can be deduced that feed rate and cutting speed had the most significant effects during machining. Details of their effects are further explained below.

In order to carry out statistical analysis, it was discovered statistically that transformation is required for these two responses (i.e., acoustic emission and surface roughness). Hence, an inverse transformation and Natura $\log (\ln )$ transformation are the most suitable for the step wise regression analysis, respectively. Detailed statistical analysis of this data is also presented below.

Table 2. Machining parameters and responses for RSA 6061

\begin{tabular}{|c|c|c|c|c|c|}
\hline Run & $\mathrm{v}(\mathrm{rpm})$ & $\mathbf{f}(\mathbf{m m} / \mathbf{m i n})$ & $\mathrm{d}(\mu \mathrm{m})$ & $\left(1 /\left(\operatorname{AE} \times 10^{\wedge}-4\right)\right) v$ & $\operatorname{Ln}(\mathbf{R a}) \mathbf{n m}$ \\
\hline Exp1 & 1750 & 25 & 25 & 0.218723 & 1.098612 \\
\hline Exp2 & 1750 & 25 & 5 & 0.450857 & 0.916291 \\
\hline Exp3 & 3000 & 5 & 15 & 0.443459 & 0.693147 \\
\hline Exp4 & 1750 & 15 & 15 & 0.412201 & 1.280934 \\
\hline Exp5 & 1750 & 15 & 15 & 0.412201 & 1.386294 \\
\hline Exp6 & 1750 & 5 & 25 & 0.899281 & 0.832909 \\
\hline Exp7 & 500 & 15 & 25 & 0.555247 & 3.583519 \\
\hline Exp8 & 3000 & 25 & 15 & 0.508647 & 0.875469 \\
\hline Exp9 & 3000 & 15 & 25 & 0.429923 & 1.098612 \\
\hline Exp10 & 500 & 25 & 15 & 0.35137 & 4.882802 \\
\hline Exp11 & 3000 & 15 & 5 & 0.503018 & 0.470004 \\
\hline Exp12 & 500 & 5 & 15 & 1.168224 & 1.098612 \\
\hline Exp13 & 1750 & 5 & 5 & 0.971817 & 0.587787 \\
\hline Exp14 & 1750 & 15 & 15 & 0.412201 & 1.335001 \\
\hline Exp15 & 500 & 15 & 5 & 0.491159 & 3.610918 \\
\hline
\end{tabular}


In this study, Response Surface Method based on second-order mathematical model was applied as written in equation 1 :

$$
Y=\beta_{0}+\beta_{1} x_{1}+\beta_{2} x_{2}+\beta_{3} x_{3}+\beta_{4} x_{4}+\beta_{5} x_{5}
$$

Where $\beta_{0}$ is the constant of the suggested regression equation, and the coefficients, $\beta_{1}, \beta_{2}, \beta_{3}, \beta_{4}$ and $\beta_{5}$ values are the approximations of corresponding parameters, $x_{1}, x_{2}$, $x_{3}, x_{4}$ and $x_{5}$ are logarithm transformation of factors such as feed rates, spindle speed and depth of cut.

From Table 3 and 4, the models gave quadratic equations with interaction effects between feed rate and cutting speed in both cases.

The p-values of cutting parameters such as speed, feed, and depth of cut show contributions to the acoustic emission (AE) and surface roughness $\left(\mathrm{R}_{\mathrm{a}}\right)$. Stepwise backward Regression analysis was carried out to further ascertain the validity of these models. The values of $\mathrm{R}^{2}$ from ANOVA in Table 3 and 4 are 0.90833 and 0.906073 , respectively. These simply indicate that the models explain $90.833 \%$ and $90.607 \%$ variations of AE signal and surface roughness, respectively. Hence, it makes the experimental models a good fit. The most significant cutting parameter is the Feed rate for both AE and Surface roughness. It contributed about $51.61 \%$ and $51.58 \%$ variation to the responses, respectively. Equations 2, 3 and 4 represent quadratic models generated from ANOVA in table 3 and 4.

Table 3. AE output from analysis of variance (ANOVA)

\begin{tabular}{|l|c|c|c|c|c|c|}
\hline \multicolumn{2}{|c|}{ Regression Statistics } & & Coefficients & Standard Error & t Stat & P-value \\
\hline Multiple R & 0.953067 & Intercept & 1.84273 & 0.161973 & 11.37675 & $1.21 \mathrm{E}-06$ \\
\hline R Square & 0.908336 & $f(\mathrm{~mm} / \mathrm{min})$ & -0.00033 & $6.46 \mathrm{E}-05$ & -5.15017 & 0.000603 \\
\hline Adjusted $\mathrm{R}^{2}$ & 0.857411 & $v(\mathrm{rpm})$ & -0.10542 & 0.016941 & -6.22315 & 0.000155 \\
\hline $\begin{array}{l}\text { Standard } \\
\text { Error }\end{array}$ & 0.09739 & $d(\mu \mathrm{m})$ & -0.00392 & 0.003443 & -1.13874 & 0.284215 \\
\hline Observations & 15 & $v f$ & $1.76 \mathrm{E}-05$ & $3.9 \mathrm{E}-06$ & 4.52839 & 0.001429 \\
\hline & & $f^{\wedge} 2$ & 0.001671 & 0.000504 & 3.315708 & 0.009002 \\
\hline
\end{tabular}

Model equation:

$$
A E(\mathrm{v})=\left(1.84273-0.00033 f-0.10542 v-00392 d+1.76^{-5} v f+0.00167 f^{2}\right)^{-1}
$$

\begin{tabular}{|c|c|c|c|c|c|c|}
\hline \multicolumn{2}{|c|}{ Regression Statistics } & & Coefficients & Standard Error & t Stat & P-value \\
\hline Multiple R & 0.951879 & Intercept & 1.794431 & 0.801811 & 2.237973 & 0.052015 \\
\hline R Square & 0.906073 & $v(\mathrm{rpm})$ & -0.00211 & 0.000674 & -3.13004 & 0.012121 \\
\hline Adjusted $\mathrm{R}^{2}$ & 0.853892 & $f(\mathrm{~mm} / \mathrm{min})$ & 0.183074 & 0.039596 & 4.62358 & 0.001248 \\
\hline Standard Error & 0.504907 & $d(\mu \mathrm{m})$ & 0.012858 & 0.017851 & 0.720299 & 0.489625 \\
\hline \multirow[t]{2}{*}{ Observations } & 15 & $v f$ & $-7.2 \mathrm{E}-05$ & $2.02 \mathrm{E}-05$ & -3.56686 & 0.006054 \\
\hline & & $v^{\wedge} 2$ & $6.25 \mathrm{E}-07$ & $1.67 \mathrm{E}-07$ & 3.737217 & 0.004645 \\
\hline
\end{tabular}

Table 4. Ra output from analysis of variance (ANOVA)

Model equations:

$$
\begin{gathered}
\ln R a(n m)=1.794431-0.00211 v+0.183074 f+0.012858 d-7.2^{5} v f+6.25^{7} v^{2} \\
R a(n m)=e^{\left(1.794431-0.00211 v+0.183074 f+0.012858 d-7.2^{5} v f+6.25^{7} v^{2}\right)}
\end{gathered}
$$


Where $\mathrm{Ra}=$ surface roughness $(\mathrm{nm}), \mathrm{AE}=$ Acoustic emission (v), $f=$ feed rate $(\mathrm{mm} / \mathrm{min}), v=$ cutting speed $(\mathrm{rpm})$ and $d=$ depth of cut $(\mu \mathrm{m})$

\subsection{Effects of Cutting Parameters}

In Fig. 3, the effect of speed was examined. It is revealed that an increase in speed, feed rate at $25 \mathrm{~mm} / \mathrm{min}$ and depth of cut at $25 \mathrm{~mm}$ resulted in a noticeable increase in voltage of acoustic emission signal. This could probably be a result of an elevated vibration from the contact between the cutting tool and the machined surface. However, in Fig. 4, an increase in cutting speed will lead to a better surface roughness of RSA 6061 even at low feed and depth of cut. These effects can also be noticed in Table 3, experimental runs 3 and 11 . At this condition, it is believed that the machined surface is free of any material spring back and high friction that could cause rapid tool wear.

Fig. 5 and Fig. 6 show the effect of feed rates on diamond turned RSA 6061. The effect of high feed rates is always severe on the machining process. Usually, high Feed rate comes with high friction associated with heat between the tool tip and material surface. Therefore, in Fig. 5, at high feed rates and low speed, poor surface roughness is recorded because large chips will be deposited on the machined surface coupled with accelerated tool edge damage due to frictional effect. In table 3, experimental runs 7 and 10 confirmed this effect. Similar patterns were noticeable via the effect of feed rates on AE Signal in Figure 5. Effect of feed on $\mathrm{Ra}$ in Figure 6 came as a result of the same cutting domain of feed rates at $(5-25) \mathrm{mm} / \mathrm{min}$ and speed at (5-25) $\mathrm{rpm}$ in the study.

Fig. 7 and Fig. 8 show the effect of depth of cut on both $\mathrm{AE}$ and Surface roughness can be noticeable but not that significant. Fig. 7 reveals an increase in depth of cut at high feed rates and speed will result in high spikes acoustic emission which can also serve as an indication for poor surface quality. Consequently, Fig. 8 shows that an increase in depth of cut will lead to severe poor surface quality, because chip thickness often cloth and scratch the machined surface at this condition. In table 3, experimental run 1 confirmed the effect of depth of cut at $25 \mathrm{~mm}$ where $\mathrm{AE}$ was seen to be high.

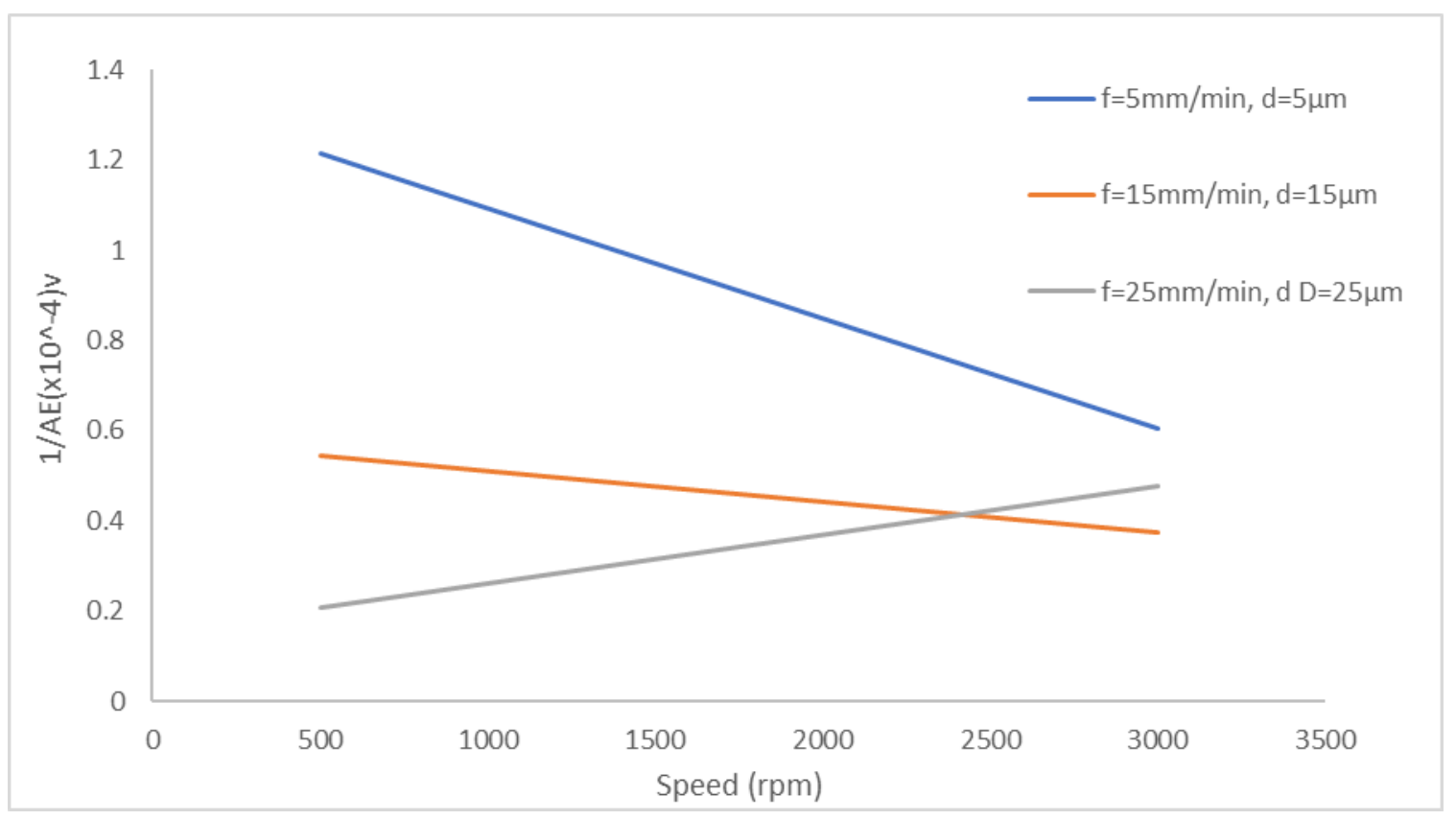

Figure 3. Effect of Cutting Speed on AE 


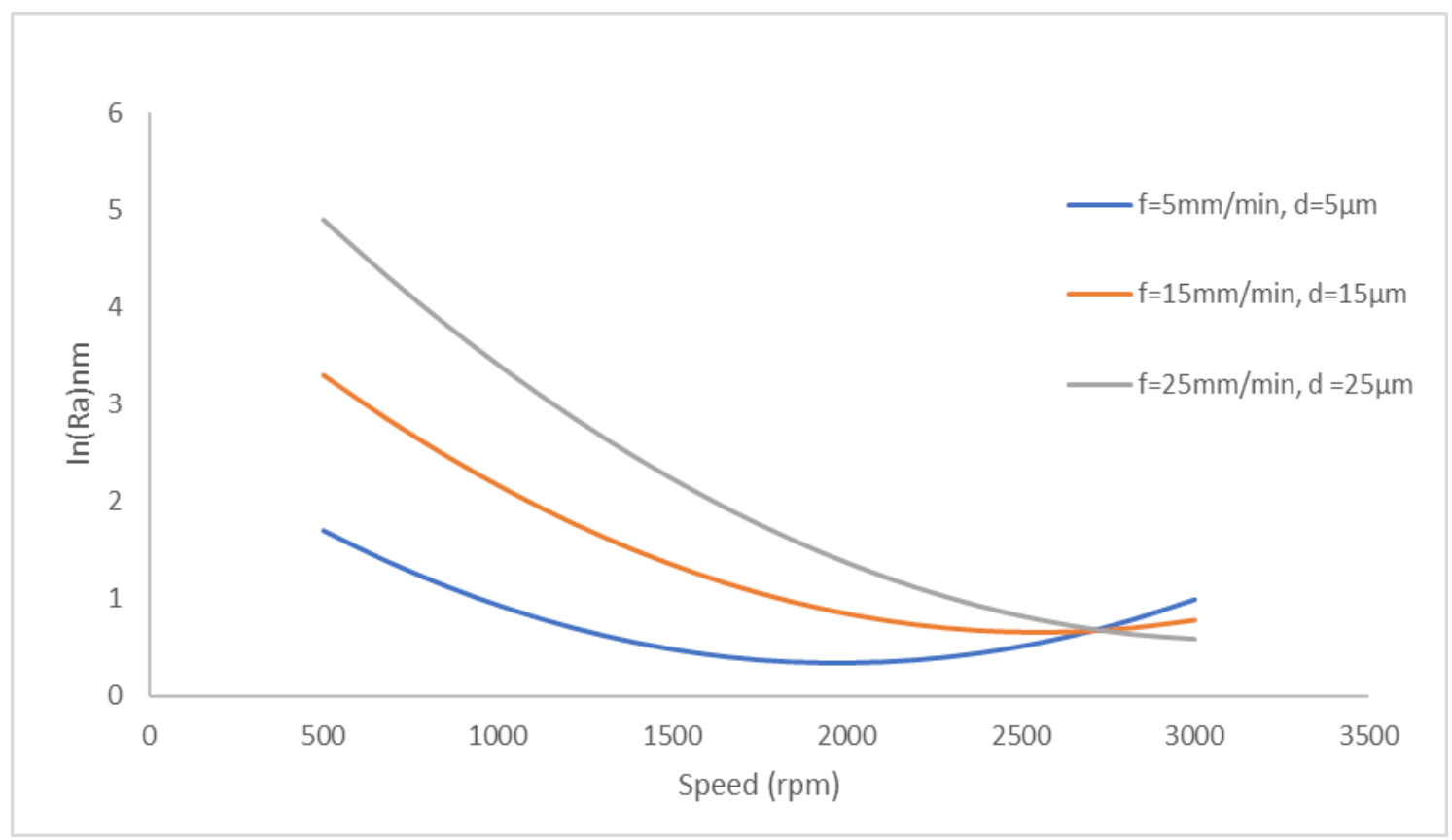

Figure 4. Effect of Cutting speed on $\mathrm{AE}$

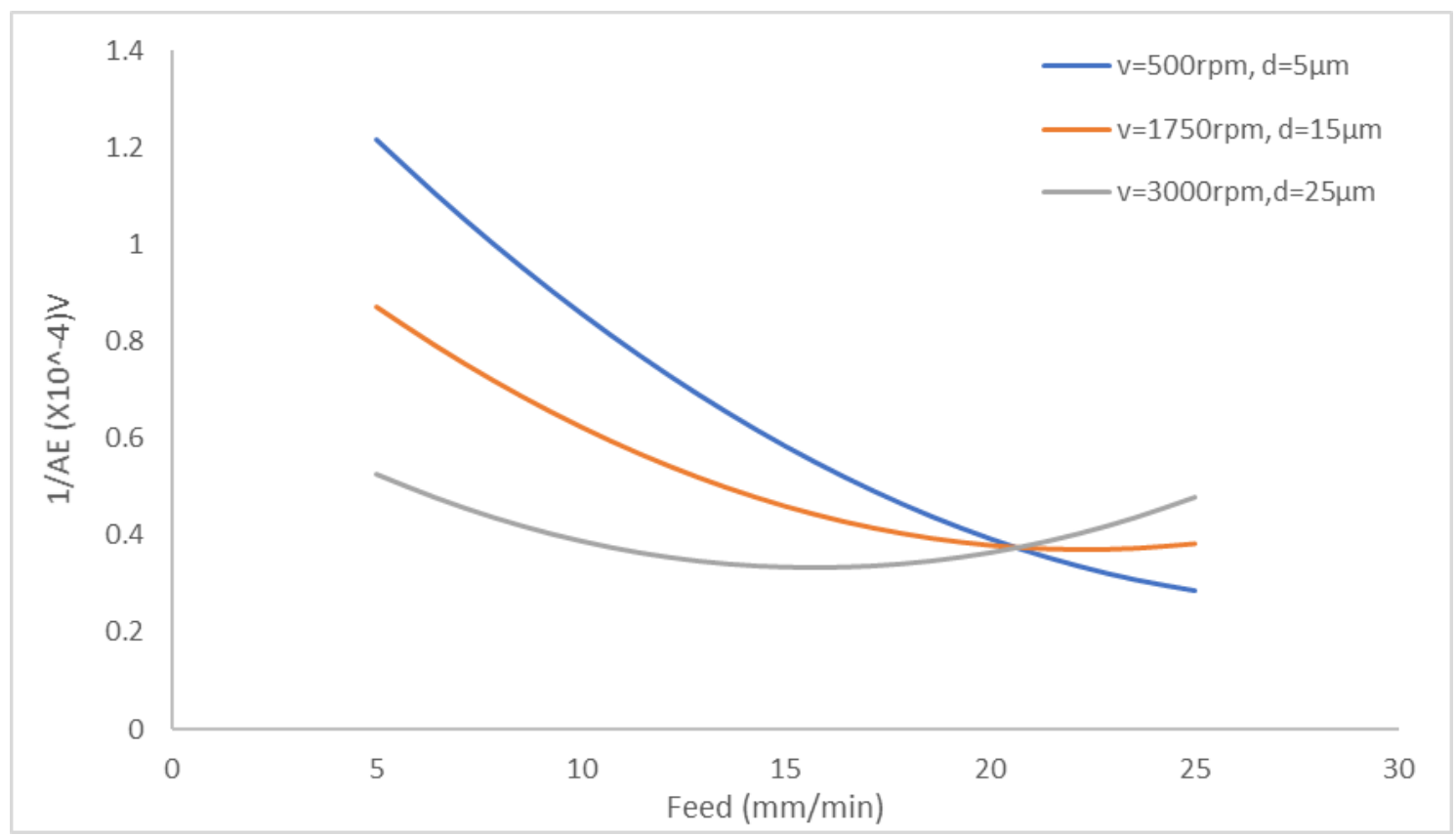

Figure 5. Effect of Feed rate on AE 


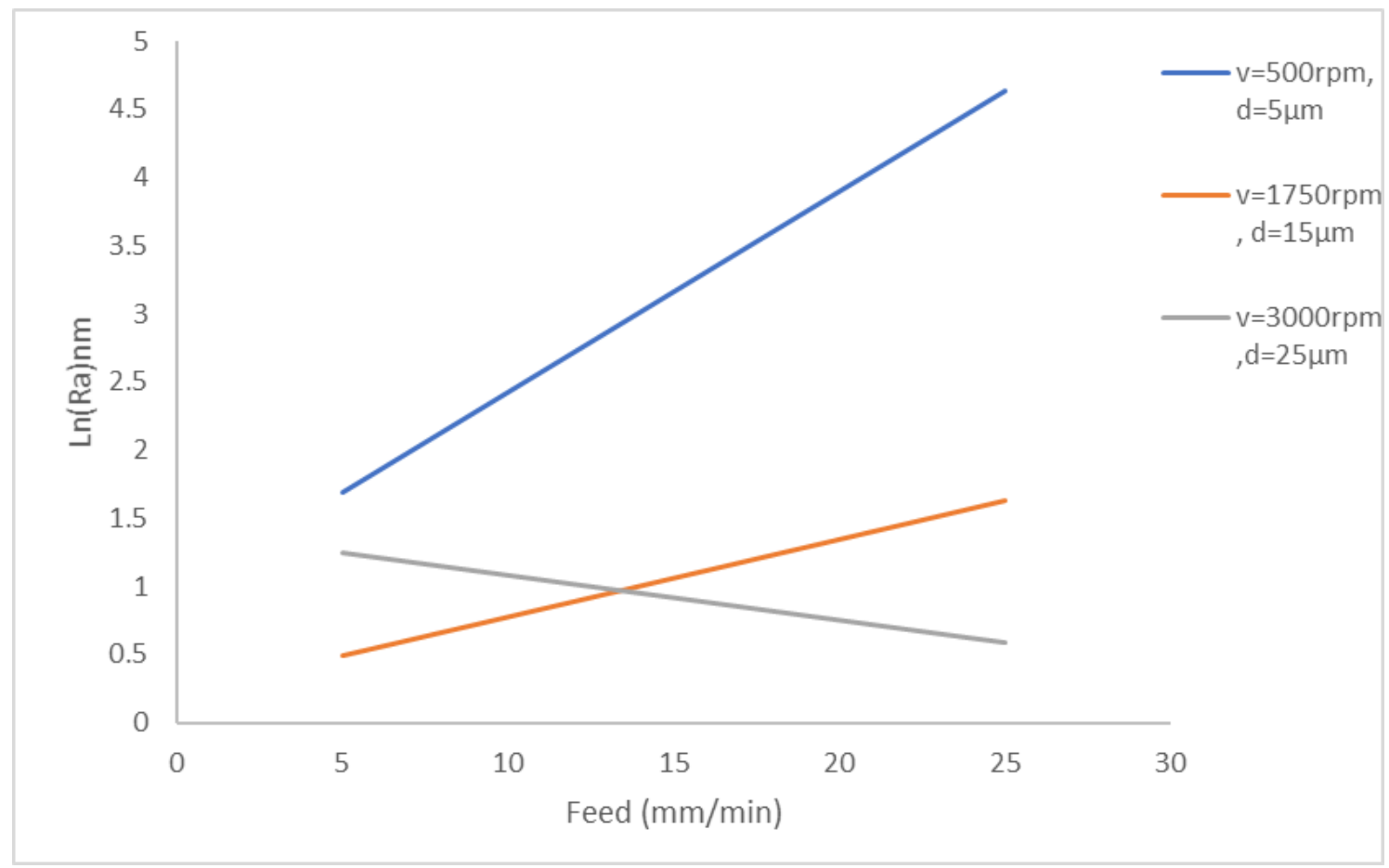

Figure 6. Effect of Feed rate on Ra

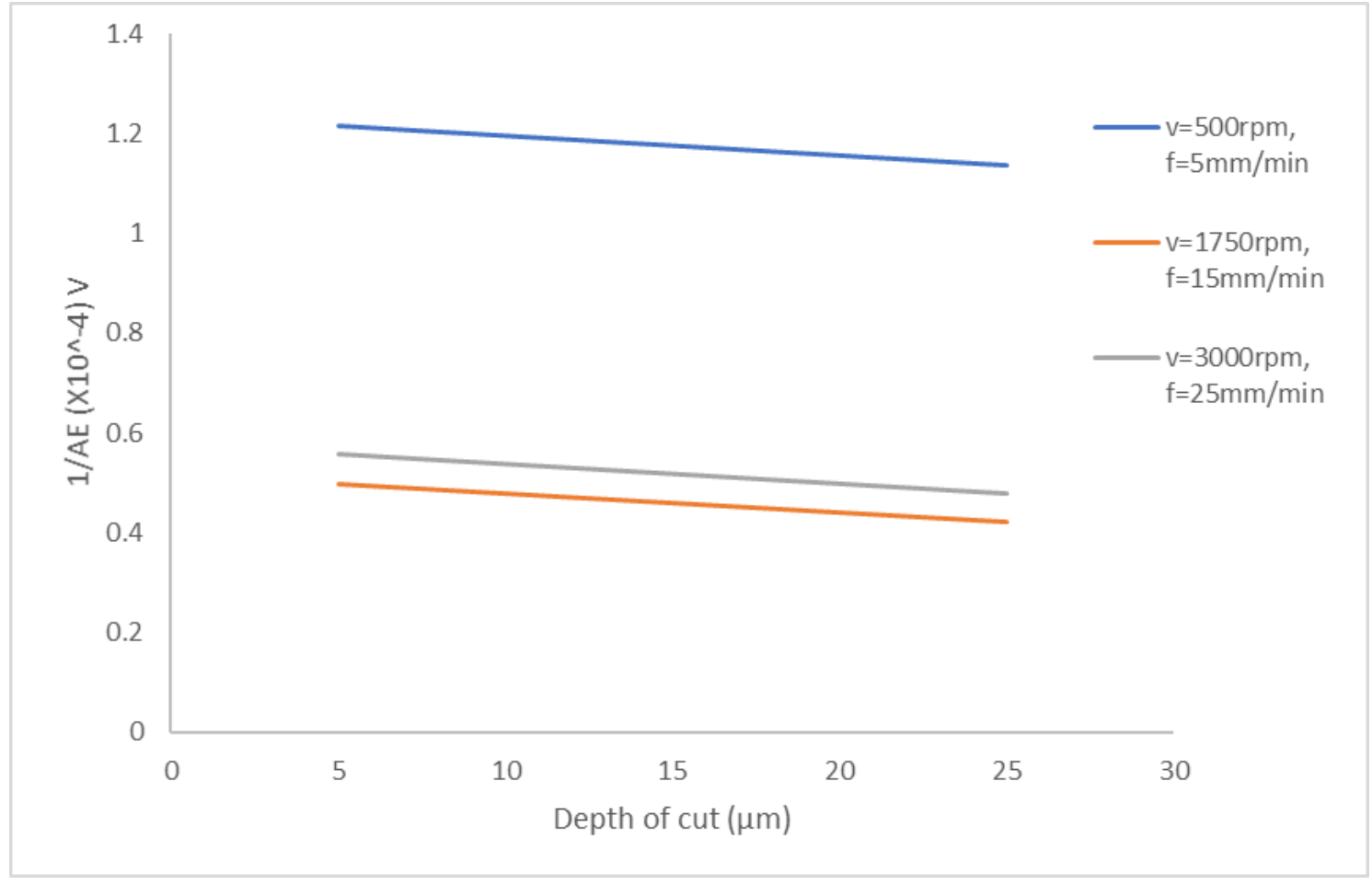

Figure 7. Effect of Depth of cut on AE 


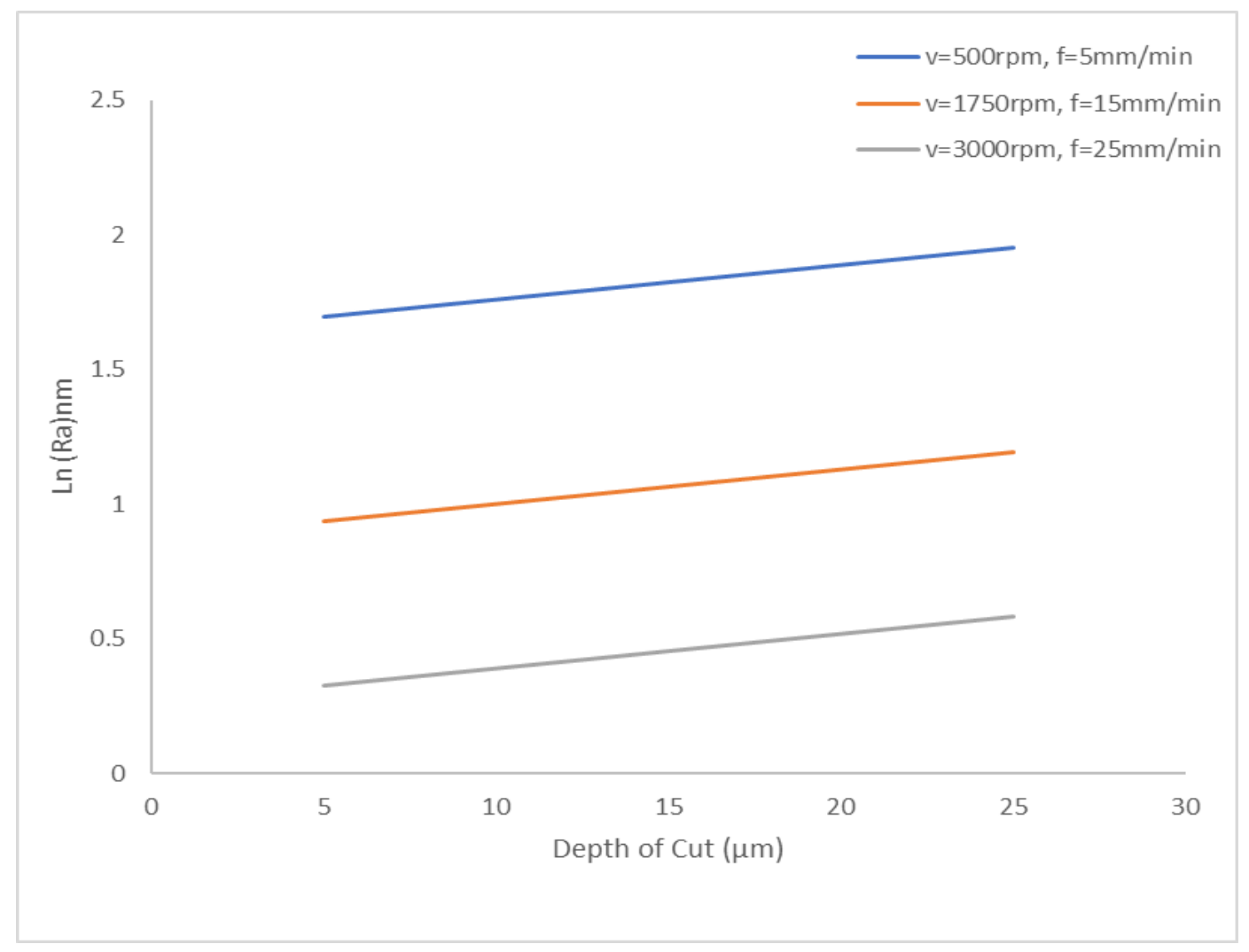

Figure 8. Effect of Depth of cut on Ra

\section{Conclusions}

This paper has presented machinability of RSA 6061 using ultra-high precision diamond turning. The focus is on surface roughness and acoustic emission of RSA 6061. The author examined the effect of cutting parameters (cutting speed, feed rate and depth of cut). ANOVA was used to develop a model for the responses and a $\mathrm{R}^{2}$ of $90.607 \%$ and $90.833 \%$ were obtained for Ra and AE, respectively. From the results on cutting parameters, the most influential parameter on surface roughness is feed rate. A high cutting speed and low feed rate was noticed to generate good quality surface. Acoustic emission signal was also noticed to be sensitive to high feed rates as well as high cutting speeds due to possible vibration and friction between the diamond tool tip and workpiece. Therefore, to monitor the performance of machined part, an attempt was made to acquire acoustic emission during diamond turning and it has been proven suitable to obtain a good quality surface finish that is less than 2nm during machining of RSA 6061 when high speed and low feed rate are combined.

\section{REFERENCES}

[1] Zhang D, Bi G, Sun Z, Guo Y. "Online monitoring of precision optics grinding using acoustic emission based on support vector machine," The International Journal of Advanced Manufacturing Technology, vol. 80, pp. 761-774, 2015.

[2] Myshkin N, Petrokovets M. "Friction, Lubrication, Wear: Physical Principles and Technical Applications of Tribology," ed: Fizmatlit, Moscow, 2007.

[3] Fadin Y A, Kireenko O, Sychev S, Breki A. "Acoustic emission and surface roughness of brittle materials," Technical Physics Letters, vol. 40, pp. 1089-1091, 2014.

[4] Al-Kindi G A, Shirinzadeh B. "An evaluation of surface roughness parameters measurement using vision-based data," International Journal of Machine Tools and Manufacture, vol. 47, pp. 697-708, 2007.

[5] Mathia T, Pawlus P, Wieczorowski M. "Recent trends in surface metrology," Wear, vol. 271, pp. 494-508, 2011.

[6] Olufayo O A, Abou-El-Hossein K. "Acoustic Emission Monitoring in Ultra-High Precision Machining of Rapidly Solidified Aluminum," in Proceedings International Conference on Competitive Manufacturing (Coma'13, 30 January-1 February 2013 Stellenbosch, South Africa), 2013, pp. 307-312.

[7] Lee D-E, Hwang I, Valente C M, Oliveira J, Dornfeld D A. "Precision manufacturing process monitoring with acoustic emission," in Condition Monitoring and Control for Intelligent Manufacturing, ed: Springer, 2006, pp. 33-54.

[8] Wang B, Liu Z. "Acoustic emission signal analysis during chip formation process in high-speed machining of 7050-T7451 aluminum alloy and Inconel 718 superalloy," Journal of Manufacturing Processes, vol. 27, pp. 114-125, 
2017.

[9] Zhong Z, Leong M, Liu X. "The wear rates and performance of three mold insert materials," Materials \& Design, vol. 32, pp. 643-648, 2011.

[10] Abou-El-Hossein K, Olufayo O. "Diamond machining of rapidly solidified aluminium for optical mould inserts," Procedia materials science, vol. 6, pp. 1077-1082, 2014.

[11] Gubbels G P, van Venrooy B W, Bosch A J, Senden R. "Rapidly solidified aluminium for optical applications," in Advanced Optical and Mechanical Technologies in Telescopes and Instrumentation, 2008, p. 70183A.

[12] Otieno T, Abou-El-Hossein K, Hsu W, Cheng Y, Mkoko Z. "Surface roughness when diamond turning RSA 905 optical aluminium," in Optical Manufacturing and Testing XI, 2015, p. 957509 .

[13] Guo Y, Ammula S. "Real-time acoustic emission monitoring for surface damage in hard machining," International Journal of Machine Tools and Manufacture, vol. 45, pp. 1622-1627, 2005.

[14] Tönshoff H, Wulfsberg J, Kals H, König W, Van Luttervelt C. "Developments and trends in monitoring and control of machining processes," CIRP Annals, vol. 37, pp. 611-622, 1988.

[15] Min S, Lidde J, Raue N, Dornfeld D. "Acoustic emission-based tool contact detection for ultra-precision machining," CIRP annals, vol. 60, pp. 141-144, 2011.

[16] Hase A, Wada M, Koga T, Mishina H. "The relationship between acoustic emission signals and cutting phenomena in turning process," The International Journal of Advanced Manufacturing Technology, vol. 70, pp. 947-955, 2014.

[17] Ravindra H, Srinivasa Y, Krishnamurthy R. "Acoustic emission for tool condition monitoring in metal cutting," Wear, vol. 212, pp. 78-84, 1997.

[18] Chen X, Mohammed A, Oluwajobi A. "Investigation of AE features in grinding," in Journal of Physics: Conference Series, 2012, p. 012090.

[19] Strömbergsson D, Marklund P, Edin E, Zeman F. "Acoustic emission monitoring of a mechanochemical surface finishing process," Tribology International, vol. 112, pp. 129-136,
2017.

[20] Onwuka G, Abou-El-Hossein K, Mkoko Z. "AE monitoring of diamond turned rapidly Soldified Aluminium 443," in Journal of Physics: Conference Series, 2017, p. 012059.

[21] Hwang T, Whitenton E P, Hsu N N, Blessing G V, Evans C J. "Acoustic emission monitoring of high-speed grinding of silicon nitride," Ultrasonics, vol. 38, pp. 614-619, 2000.

[22] Hweju Z, Abou-El-Hossein K. "Surface Roughness Prediction Based on Acoustic Emission Signals in High-Precision Diamond Turning of Rapidly Solidified Optical Aluminum Grade (RSA443)," in Key Engineering Materials, 2020, pp. 363-368.

[23] Pawade R, Joshi S. "Analysis of acoustic emission signals and surface integrity in the high-speed turning of Inconel 718," Proceedings of the Institution of Mechanical Engineers, Part B: Journal of Engineering Manufacture, vol. 226, pp. 3-27, 2012.

[24] Otieno T, Abou-El-Hossein K. "Cutting forces and acoustic emission in the diamond turning of rapidly-solidified aluminium," Insight-Non-Destructive Testing and Condition Monitoring, vol. 60, pp. 11-18, 2018.

[25] Cheng Y-C, Hsu W-Y, Abou-El-Hossein K, Olufayo O, Otieno T. "Investigation of diamond turning of rapidly solidified aluminum alloys," in Current Developments in Lens Design and Optical Engineering XV, 2014, p. 919214.

[26] Otieno T. "The machinability of rapidly solidified aluminium alloy for optical mould inserts," Nelson Mandela University, 2018.

[27] Kadirgama K, Noor M, Rahman M, Rejab M, Haron C H C, Abou-El-Hossein K A. "Surface roughness prediction model of 6061-T6 aluminium alloy machining using statistical method," 2009.

[28] Abou-El-Hossein K, Olufayo O, Mkoko Z. "Diamond tool wear during ultra-high precision machining of rapidly solidified aluminium RSA 905," Wear, vol. 302, pp. 1105-1112, 2013.

[29] Gubbels G, Tegelaers L, Senden R. "Melt spun aluminium alloys for moulding optics," in Optifab 2013, 2013, p. $88841 \mathrm{~W}$. 